\title{
¿Qué es el Brexit? Origen y posibles consecuencias
}

\author{
What is Brexit? Origin and Possible Consequences
}

\author{
Soledad Torrecuadrada García-Lozano* \\ Pedro García Fuente**
}

\author{
SUMARIO: I. Introducción. II. El Reino Unido en la Unión Europea. \\ III. Consecuencias del Brexit. IV. Conclusiones. V. Bibliografía.
}

* Catedrática acreditada en Derecho Internacional y Relaciones Internacionales por el Ministerio de Educación, Cultura y Deporte de España (2 de julio de 2012); doctora en Derecho por la Universidad Autónoma de Madrid; Máster en Relaciones Internacionales por el Instituto Universitario de Investigación Ortega y Gasset de Madrid, y Diploma del Centro de Investigación de la Academia de Derecho Internacional de La Haya (Holanda). Actualmente, labora como profesora titular de Derecho Internacional y Relaciones Internacionales en la Facultad de Derecho de la Universidad Autónoma de Madrid.

** Contratado predoctoral en el Área de Derecho Internacional Público de la Universidad Autónoma de Madrid, en el marco del programa FPU del Ministerio de Educación, Cultura y Deporte de España (FPU 13/04845); licenciado en Derecho y Ciencias Políticas y de la Administración por la Universidad Autónoma de Madrid, y Máster en Derecho Internacional Público y Relaciones Internacionales por la Universidad Internacional Menéndez Pelayo.

Artículo recibido el 19 de julio de 2016 Aprobado para publicación el 22 de septiembre de 2016

D. R. (C) 2017. Universidad Nacional Autónoma de México-Instituto de Investigaciones Jurídicas. Anuario Mexicano de Derecho Internacional, vol. XVII, 2017, pp. 3-40

México, D. F., ISSN 1870-4654 
Resumen: La retirada del Reino Unido de la Unión Europea es una cuestión de máxima actualidad que ha sembrado de incertidumbres a los estudiosos, por tratarse de un objeto de análisis insospechado hasta el anuncio por parte del primer ministro británico de la realización de un referéndum sobre esta cuestión. Las negociaciones en las que se articulará la futura relación entre la organización y el Estado que no desea seguir participando en ella como miembro pondrá a prueba la fortaleza de la Unión Europea. En este trabajo intentamos entender los factores que han rodeado al Brexit, así como las eventuales consecuencias del mismo, siendo conscientes de que aún no se han iniciado las negociaciones que concluirán con el modelo relacional futuro. En todo caso, nuestra intención es identificar algunos ámbitos materiales que se verán afectados por ellas sin aportar más soluciones que las que nos permita el análisis jurídico de la situación en presencia.

Palabras clave: Unión Europea, Estados miembros, procedimiento de retirada, política comercial común, acción exterior, política común de seguridad y defensa.

ABSTRACT: The British withdrawal from the European Union is an extremely topical issue, casting doubts in the scholars as we are facing a new subject that had been unsuspected until the Prime Minister of the United Kingdom announced a referendum on the country's permanence in the Union. The negotiations on the future relationship of the United Kingdom and the European Union will test the strength of the Organization in front of the leaving country. This paper addresses the main factors surrounding the Brexit decision and its eventual implications, bearing in mind that the negotiations have not yet begun. In any case, it is the authors' purpose to identify some policy areas which will be necessarily affected in this process, without providing more solutions than those arising from the legal analysis of the given situation.

Key words: European Union, Members States, withdrawal procedure, Common Commercial Policy, External Action, Common Security and Defense Policy.

RÉSUMÉ: La sortie du Royaume-Uni de l'Union Européenne est une question en actualité qui a semé d'incertitudes les experts, il s'agit d'un objet d'étude insoupçonné jusqu'à l'annonce du Premier ministre britannique de la réalisation d'un referendum sur cette question. Les négociations dans lesquelles va s'articuler la future relation entre l'organisation et l'Etat qui ne veut plus participer dans celle-ci comme membre seront une preuve pour la force de l'Union Européenne. Dans ce travail, on essaye de comprendre les facteurs du Brexit, ainsi que les éventuelles conséquences de celui-ci, tout en étant conscients du fait que les négociations n’ont pas commencé mais celles-ci finiront avec le nouvel modèle de relations. En tout cas, notre intention est d'identifier certains cadres matériaux qui vont se voir affecter par celles-ci sans donner plus de réponses que celles que l'analyse juridique de la situation en présence.

Mots-clés: Union Européenne, états membres, procédure de sortie, politique commerciale commune, action extérieure, politique de sécurité et de défense commune. 


\section{INTRODUCCIÓN}

Durante junio de 2016 una de las palabras más veces impresas en los diarios de todo el mundo ha sido Brexit, para referirse a uno de los posibles resultados del referéndum convocado el día 23 en el Reino Unido, para decidir acerca de su permanencia como Estado miembro de la Unión Europea (UE) o su salida de esta organización internacional. ${ }^{1}$ Antes de la consulta popular se hablaba de la campaña desarrollada por los defensores de una u otra opción, mientras que en los días posteriores las menciones se sitúan en el eje de los posibles escenarios ante los que nos encontraremos en el futuro. Si bien la campaña concluía con la votación, lo ocurrido tras el escrutinio nos conduce a una incertidumbre que no podremos resolver fácilmente.

Ciertamente, el referéndum convocado en el Reino Unido hacía a sus ciudadanos decantarse entre una opción conocida, la permanencia en la UE, o un futuro incierto, por cuanto las condiciones en las que la salida del Estado miembro se materialicen en el futuro serán el resultado de una negociación, tal y como establece el artículo 50 del Tratado sobre la Unión Europea (TUE). Precepto de breve recorrido, pues se incorporó en la última modificación de los tratados constitutivos, concretada con el Tratado de Lisboa (adoptado el 13 de diciembre de 2007), en vigor desde el 1o. de noviembre de 2009. ${ }^{2}$

Si bien esta cláusula es relativamente joven, antes de ella se habían producido reducciones en el ámbito espacial de aplicación del derecho de la Unión Europea. El primero en el tiempo fue el de Argelia, pues cuando se crearon las Comunidades Europeas, precedentes inmediatas de la UE, Argelia era parte de Francia. ${ }^{3}$ Debido al momento en el que se produjo

1 En realidad se trata de una contracción entre Great Britain y exit, lo que demuestra claramente, que la intención de quienes idearon este término no era precisamente el mantenimiento dentro de la Unión Europea.

2 La versión consolidada de los tratados constitutivos con el Tratado de Lisboa puede verse en Diario Oficial de la Unión Europea, núm. C202, del 7 de junio de 2016.

3 Francia reconoció a Argelia como Estado en la Declaración General de las Dos Delegaciones del 18 de marzo de 1962, cuyo texto puede leerse en la página del presidente de la República de Argelia, http: / / www.el-mouradia.dz / francais/algerie/ histoire/accord\%20evian.htm. 
Esta revista forma parte del acervo de la Biblioteca Jurídica Virtual del Instituto de Investigaciones Jurídicas de la UNAM

esta retirada, con un mercado común incipiente que apenas comenzaba su andadura, el precedente argelino no es de una gran relevancia práctica para la situación actual, aunque sí de mención obligada.

Más tarde vendría la retirada de Groenlandia, ${ }^{4}$ territorio danés dotado de un autogobierno que se ha ido incrementando progresivamente, habitado en su mayoría por groenlandeses descendientes del pueblo inuit. En 1979 el gobierno danés otorgó a la isla un estatuto de autonomía, cuyo alcance se vio ampliado en 2008 como consecuencia de un referéndum organizado sobre este particular. ${ }^{5}$ En los treinta años que separan las fechas recién indicadas, se produjo una consulta de especial relevancia para este trabajo: la relativa a la continuidad de la aplicación del derecho comunitario a Groenlandia, el 23 de febrero de 1982. El resultado de este referéndum consultivo se decantó por la retirada y, tras la elaboración de un acuerdo en el que se establecían las futuras relaciones entre las entonces Comunidades Europeas y Groenlandia ${ }^{6}$ (que entró en vigor el 1o. de enero de 1985), esta última pasó a ser considerada territorio de ultramar de un Estado miembro.

Este es un antecedente más relevante, pues fue la primera ocasión en la que se aplicó un procedimiento similar al introducido casi treinta años después en el TUE. En la actualidad, la isla se menciona expresamente en un artículo del Tratado de Funcionamiento de la Unión Europea (TFUE), el 204, que establece la aplicabilidad del régimen propio de los territorios de Ultramar de los que forma parte, en tanto que territorio no europeo que mantiene "relaciones especiales con Dinamarca...", y uno de sus Protocolos (el núm. 34). ${ }^{7}$

De lo anterior se desprenden dos conclusiones: una, la posibilidad de retirada parcial de un Estado miembro, y dos, la necesidad de negociación

4 Dinamarca accedió al estatuto de miembro de las Comunidades Europeas en la misma fecha que el Reino Unido, de modo que el Derecho comunitario era aplicable a todo el territorio danés, incluido el de esta gran isla ubicada en el noreste del continente americano, denominada Kalaallit Nunaat en idioma groenlandés.

5 Véase el informe de IWGIA de 2016, http://www.iwgia.org/images/stories/sections-esp/ regiones/arctico/docs/MI2016/Groenlandia_MI2016_web.pdf.

6 Es el tratado del 13 de marzo de 1984, que modifica los tratados comunitarios y se puede ver en Diario Oficial, núm. L 29, del 1o. de febrero de 1985, pp. 1 y ss. El mismo ejemplar incorporan los documentos que establecen las nuevas bases de la relación entre Dinamarca y Groenlandia dentro de las Comunidades Europeas.

7 Como toda Declaración o Protocolo es un Documento anexo a los Tratados Constitutivos, véase supra nota núm. 2. 
para establecer la finalización de la aplicación del derecho de la Unión Europea a un territorio al que hasta entonces resultara exigible. La viabilidad jurídica de esta posibilidad se contemplaba incluso antes del Tratado de Lisboa, al margen de las dificultades prácticas derivadas de la integración de las economías de los Estados miembros. Recordemos que los Tratados Constitutivos guardaban silencio en este punto y, de conformidad con el artículo 56 de la Convención de Viena de 1969 sobre el Derecho de los Tratados, ${ }^{8}$ esta ausencia de previsión per se no puede interpretarse como una negativa, siempre que de algún modo "conste que fue intención de las partes admitir la posibilidad de denuncia o de retiro; o, b) que el derecho de denuncia o de retiro pueda inferirse de la naturaleza del Tratado".

El único aspecto procedimental que indica la Convención de 1969 al respecto es la previa notificación de su intención "con doce meses, por lo menos", a la efectiva retirada. Con ello se pretende proteger la seguridad jurídica y en concreto los derechos de los Estados parte, y permitir que establezcan las bases para acomodar sus respectivos comportamientos a la nueva realidad.

Con ocasión de la entrada en vigor del Tratado de Lisboa el primer día de noviembre de 2009, la posibilidad jurídica queda esclarecida al incorporarse una disposición en ese sentido: el artículo 50 del TUE, que además se concibe como un derecho de los Estados, que deberán adoptar la decisión "de conformidad con sus normas constitucionales". El procedimiento establecido al efecto no se encuentra demasiado desarrollado, aunque se inicia con la notificación de la retirada por parte del Estado miembro al Consejo Europeo, ${ }^{9}$ que adoptará las directrices de la negociación que se iniciará (según el mismo artículo 50) a continuación, con el propósito de acordar:

La forma de su retirada, teniendo en cuenta el marco de sus relaciones futuras con la Unión... El Consejo ${ }^{10}$ lo celebrará en nombre de la Unión por mayoría

8 Convención de Viena sobre el Derecho de los Tratados, del 23 de mayo de 1969, United Nations Treaty Series vol. 1155, p. 331.

9 Recordemos que el Consejo Europeo está compuesto por los jefes de Estado o de gobierno de los Estados miembros, así como por su presidente y por el presidente de la Comisión, de acuerdo con el artículo 15 del TUE. Esta institución impulsa el desarrollo de la Unión y define sus orientaciones y prioridades políticas generales, pero no ejerce funciones legislativas.

10 Nótese la intervención en este punto del Consejo, al que también nos referimos como Consejo de la Unión Europea —institución diferente del Consejo Europeo-, compuesto 
Esta revista forma parte del acervo de la Biblioteca Jurídica Virtual del Instituto de Investigaciones Jurídicas de la UNAM

cualificada, previa aprobación del Parlamento Europeo. Los Tratados dejarán de aplicarse al Estado de que se trate a partir de la fecha de entrada en vigor del acuerdo de retirada o, en su defecto, a los dos años de la notificación a que se refiere el apartado 2, salvo si el Consejo Europeo, de acuerdo con dicho Estado, decide por unanimidad prorrogar dicho plazo.

Las instituciones de la Unión Europea que participan en este procedimiento, según el artículo 218 del TFUE, lo harán con la ausencia de los representantes del Estado que desea apartarse de la Unión. Se trata de una exclusión evidente, pues de lo contrario aquel se encontraría en las dos posiciones negociadoras: como auténtico protagonista y como miembro de la Organización.

La futura relación del Reino Unido con la UE es incierta, máxime cuando el interesado aún no ha presentado la solicitud, lo que aparentemente realizará a principios de 2017. Descartada ya la opción defendida por algunos de quienes se mostraron a favor del Brexit a través de la plataforma denominada Bregret con el propósito de que se celebre un nuevo referéndum, ${ }^{11}$ hay quienes se sienten engañados por el reconocimiento por parte de los políticos defensores del Brexit de la imposibilidad de poner en práctica las medidas prometidas durante la campaña del referéndum. ${ }^{12}$

Este trabajo se puede considerar un estudio sobre un futurible que no es tal, pues en él pretendemos ubicar bajo la lente del microscopio la evolución de las relaciones entre el Reino Unido y la UE, así como las eventuales consecuencias del resultado de la consulta británica, conscientes de que sólo el tiempo dirá si se materializan en la práctica, dependiendo de las próximas negociaciones. Para lograr nuestro objetivo, en primer lugar estudiaremos la posición del Reino Unido dentro de esta organización internacional, para pasar a continuación a analizar las consecuencias de su salida centrándonos en el impacto del Brexit en ámbitos materiales concretos como la acción

por los ministros responsables por razón de materia de cada Estado miembro, y que ejerce funciones legislativas y presupuestarias en conjunción con el Parlamento Europeo, de acuerdo con el artículo 16 del TUE.

11 La noticia se ha publicado en múltiples medios de comunicación, véase entre ellos: http://www.jornada.unam.mx/2016/06/26/mundo/017n1mun.

12 Véase Fresneda, Carlos, "Las mentiras del Brexit", El Mundo, 26 de junio de 2016, disponible en: http://www.elmundo.es/internacional/2016/06/26/576ec5a8468aeb11758b46 2e.html. 
Esta revista forma parte del acervo de la Biblioteca Jurídica Virtual del Instituto de Investigaciones Jurídicas de la UNAM

exterior, con énfasis en su vertiente comercial, y la política de seguridad y defensa, terminando con unas breves conclusiones.

\section{EL REINO UNIDO EN LA UNIÓN EUROPEA}

\section{Evolución de la relación entre el Reino Unido y la Unión Europea}

El Reino Unido nunca ha sido visto como un Estado europeísta. De hecho, aunque en los años previos a la Segunda Guerra Mundial se mostró como un firme defensor de la creación de una organización internacional de cooperación en Europa, ${ }^{13}$ como miembro de la UE su papel se ha caracterizado por el escepticismo respecto de la construcción europea. Ello a pesar de que, al finalizar la Segunda Guerra Mundial, fue Winston Churchill quien propugnó "construir una especie de Estados Unidos de Europa, la única manera de que cientos de millones de trabajadores sean capaces de recuperar las sencillas alegrías y esperanzas que hacen que la vida merezca la pena”. ${ }^{14}$

Por sus palabras y comportamientos (impulsó la creación del movimiento Europa Unida), el primer ministro británico se considera uno de los padres fundadores de la actual Unión Europea. A pesar de ello, la actitud del Reino Unido siempre fue tibia, pues sus intereses se encontraban lejos de Europa: en la Commonwealth. De hecho, su reacción a la creación de las Comunidades Europeas fue la organización de la Asociación Europea de Libre Comercio (EFTA, por sus siglas en inglés), que tenía el propósito que más les interesaba: la creación de un espacio de cooperación económica y libre mercado entre sus Estados miembros. ${ }^{15}$ Permaneció como miem-

13 Véase Mangas Martín, Araceli y Liñán Nogueras, Diego Javier, Instituciones y derecho de la Unión Europea, Madrid, McGraw Hill, 1996, pp. 3-10 (8a. ed., Madrid, Tecnos, 2014, pp. 27 31); Fernández Navarrete, Donato y Fernández Egea, Rosa María, Historia de la Unión Europea. España como Estado miembro, Madrid, Delta, 2010, pp. 3-78; o Alcaide Fernández, Joaquín y Casado Raigón, Rafael (coords.), Curso de Derecho de la Unión Europea, Madrid, Tecnos, 2011, pp. 33-38.

14 Véase en Comisión Europea, "Winston Churchill: defensor de los Estados Unidos de Europa”, http: / / europa.eu/about-eu/eu-history/founding-fathers/pdf/winston_churchill_es.pdf.

15 Inicialmente fueron Austria, Dinamarca, Noruega, Portugal, Suecia, Suiza y Reino Unido, de los que en la actualidad permanecen como miembros de la EFTA tan solo Noruega, Suiza, Liechtenstein e Islandia. Los cuatro países forman entre sí una zona de libre comercio, 
Esta revista forma parte del acervo de la Biblioteca Jurídica Virtual del Instituto de Investigaciones Jurídicas de la UNAM

bro de esta asociación hasta su adhesión a las Comunidades Europeas, que se materializó el primero de enero de 1973, junto con las de Dinamarca e Irlanda.

No podemos obviar que desde sus inicios la permanencia del Reino Unido en la construcción europea resultó controvertida, especialmente si tenemos en cuenta que, dos años después de materializarse su adhesión a ella, se celebró el primer referéndum sobre su continuidad. ${ }^{16}$ La celebración de la consulta respondió a la promesa electoral del Partido Laborista durante las elecciones, que una vez alcanzado el gobierno defendieron el mantenimiento británico en la Organización Internacional, opción respaldada por el 67\% de los votantes. ${ }^{17}$ También notables líderes del Partido Conservador apoyaron la entrada y permanencia en las Comunidades Europeas, entre ellos Margaret Thatcher. Pero incluso cuando el mercado común era visto con buenos ojos, no dejaron pasar la oportunidad de mostrar su desacuerdo con el funcionamiento de la Organización, verbalizado en el "I want my money back"18 con el que Thatcher se opuso a que el Reino Unido aportara más fondos a los presupuestos comunitarios de los que luego recibía.

Los sucesivos gobiernos británicos han sabido emplear sus reticencias respecto de la UE con el propósito de mejorar su estatuto de miembro, de modo que con las modificaciones de los tratados constitutivos se ha ido perfilando su estatuto particular y diferenciado en el seno de las Comunidades Europeas primero, y de la Unión Europea más tarde. Así, no sólo ha permanecido voluntariamente al margen de algunas políticas de esta organización internacional, sino que también ha logrado algunos tratos de

al tiempo que participan en el mercado común de la UE de distintas maneras: Noruega, Liechtenstein e Islandia a través el Espacio Económico Europeo; Suiza a través de un centenar de acuerdos bilaterales. Véase la página oficial de esta asociación en: http: / www.efta.int/.

16 Véase en House of Commons Library, European Union (Referendum) Bill, Bill 11 of 2013-14, Research Paper, 13/41, 28 de junio de 2013, pp. 8 y ss., www.parliament.uk/briefingpapers/RP13-41.pdf.

17 Disponible en: http://news.bbc.co.uk/onthisday/hi/dates/stories/june/6/newsid2499000/ 2499297.stm.

18 Esta actitud de alguna manera contradictoria entre manifestaciones de europeísmo y euroescepticismo por parte de la primera ministra británica se encuentra bien resumida en Fralon, J. A., "Margaret Thatcher: 'I want my money back'”, Le Monde, 11 de mayo de 2005, http: / / www.lemonde.fr/europe / article / 2005/05/11/30-novembre-1979-margaret-thatcher-iwant-my-money-back_648386_3214.html. 
Esta revista forma parte del acervo de la Biblioteca Jurídica Virtual del Instituto de Investigaciones Jurídicas de la UNAM

favor nada desdeñables. ${ }^{19}$ Sirva como ejemplo su no participación en la Eurozona, compuesta por diecinueve de los Estados miembros. ${ }^{20}$

El anterior no es, sin embargo, el único ámbito material en el que el Reino Unido no ha participado. Cuando se realiza el Tratado de Maastrich (1992), la UE se encontraba en la segunda fase de la unión económica y monetaria, en la que todos los Estados miembros estaban obligados a participar, pero algunos (Reino Unido entre ellos) no desearon pasar a la tercera etapa, lo que le permitió (entre otros) conservar su moneda propia. En consecuencia, se anexa al Tratado indicado un protocolo en virtud del cual se excluye al Reino Unido de este compromiso, previendo que en caso de cambiar de opinión en este punto, podría comunicarlo antes del primer día del año 1998. ${ }^{21}$ Esta primera quiebra de la uniformidad en la aplicación del derecho de la UE posee también implicaciones institucionales, pues el Estado así excluido no puede participar en las decisiones del Consejo que se refieran a una política de la que voluntariamente decide apartarse.

Con ocasión del Tratado de Maastricht la Comunidad Económica Europea deja de ser económica, convirtiéndose en la Comunidad Europea, al incorporarse en los tratados consideraciones relativas a la ciudadanía europea. Junto con ella se añade la política social a los tratados constitutivos, con el propósito de acomodar la normativa comunitaria a la Carta social de 1989. Esta incorporación ubica al Reino Unido frente a los entonces 11 Estados parte restantes. Para resolver esta situación se celebra un protocolo (anexo igualmente al tratado) en el que se establece un doble acuerdo: por una parte los 12 Estados miembros (incluido Reino Unido) autorizan a los 11 que deseaban incorporar la política social en el tratado a utilizar las instituciones y el derecho comunitario en este ámbito material; por otra parte, al Reino Unido no le van a resultar de aplicación las normas y

19 Véase, en este sentido, Mangas Martín, Araceli, "Dilemas del Reino Unido y de la Unión Europea ¿salir o cambiar la Unión?”, Real Instituto Elcano, Documento de Trabajo 3/2016, 25 de febrero de 2016, p. 3.

20 Cerca del $68 \%$ de los Estados miembros tienen el euro como moneda oficial. Siete de los que figuran en el 32\% restante, se encuentran al margen por no cumplir las condiciones establecidas para asumir el euro (Bulgaria, Croacia, República Checa, Hungría, Polonia, Rumanía y Suecia). Sólo los dos restantes (Dinamarca y Reino Unido) lo hacen por propia voluntad.

${ }^{21}$ Es el Protocolo núm. 15 sobre determinadas disposiciones relativas al Reino Unido de Gran Bretaña e Irlanda del Norte, anexo a los Tratados Constitutivos, supra nota núm. 2. 
Esta revista forma parte del acervo de la Biblioteca Jurídica Virtual del Instituto de Investigaciones Jurídicas de la UNAM www.juridicas.unam.mx

decisiones alcanzadas, por lo que no participa en las discusiones ni en el procedimiento decisorio. Ello supone, en primer lugar, la modificación de las reglas de la mayoría cualificada a la ausencia del Reino Unido, cuando se traten estos asuntos; en segundo término, que los gastos derivados de la política social serán sufragados exclusivamente por los Estados que participen en ella.

ElTratado de Ámsterdam (1997) modificó de nuevo los tratados constitutivos y amplió los ámbitos materiales con un régimen particular para el Reino Unido. Ello fue consecuencia de la integración del Acuerdo Schengen en el marco comunitario, ${ }^{22}$ puesto que las materias objeto de este acuerdo pasaron a ser objeto de cooperación intergubernamental en el marco del TUE y sus normas previas se incorporaron al derecho comunitario. De nuevo, un Protocolo adoptado al efecto establecía idéntica solución que los precedentes en lo relativo a la adopción de decisiones en estas materias y, además, se permitía al Reino Unido aplicar en su territorio, si así lo decidía, las decisiones adoptadas por el resto de Estados miembros. El hecho de mantenerse al margen del Acuerdo de Schengen suponía mantener la capacidad para ejercer controles en sus fronteras respecto de los nacionales de cualquier Estado miembro de la Unión, al tiempo que el resto de los Estados miembros podían hacer lo propio respecto de los nacionales británicos.

En el Tratado de Niza no se añaden ámbitos sometidos a un régimen particular para el Reino Unido, y concluimos este periplo histórico con la entrada en vigor el 1o. de noviembre de 2009 del Tratado de Lisboa, la última modificación de los tratados constitutivos, en el que se mantienen las excepciones anteriores, añadiéndose dos protocolos que afectan a Reino Unido. El primero de ellos se refiere a su posición, junto con Irlanda, respecto de las políticas relativas a los controles fronterizos, al asilo y a la

22 El Acuerdo de Schengen se había celebrado en 1985 y entró en vigor en 1995. Su consecuencia básica se presenta en el ámbito de la libre circulación, al consistir en el traslado de las fronteras exteriores de la Unión Europea a los límites de sus Estados miembros con terceros Estados no miembros, creando la ficción de la inexistencia de fronteras para la circulación de ciudadanos de la Unión Europea. Curiosamente, en el Acuerdo Schengen cuentan con el estatuto de parte Islandia, Liechtenstein, Noruega y Suiza (actuales únicos miembros de la EFTA), pero no el Reino Unido. Véase información al respecto en http: / / eur-lex.europa. eu/legal-content / ES / TXT/?uri=URISERV\%3A133020. Sin embargo, los Acuerdos de Schengen exceden la libre circulación, en la medida en que incorpora cooperación policial y judicial en materia penal o el Sistema de información de Schengen, que suponía una base de datos única para todos los Estados miembros de la Unión. 
inmigración, así como respecto de la cooperación judicial en materia civil y de la cooperación policial, en el que se plasma su régimen especial respecto del Acuerdo Schengen.

El segundo se refiere a la aplicación de la Carta de Derechos Fundamentales de la Unión Europea y alcanza tanto al Reino Unido como a Polonia, cuyo artículo primero establece que "nada de lo dispuesto en el título IV de la Carta crea derechos que se puedan defender ante los órganos jurisdiccionales de Polonia o del Reino Unido, salvo en la medida en que Polonia o el Reino Unido hayan contemplado dichos derechos en su legislación nacional". Esto cuestiona la consideración del contenido de la Carta como derecho europeo (a pesar del artículo 6.1 delTUE), en la medida en que la aplicación de sus disposiciones se caracteriza por el principio de primacía. ${ }^{23}$

Pese a todo, se puede decir que no son tantos los ámbitos materiales afectados por las exclusiones británicas, teniendo en cuenta que la Unión Europea supone la existencia de un mercado único para la circulación de mercancías, ciudadanos y capitales, así como un gran territorio caracterizado por el derecho a la libre competencia (algo en lo que el Reino Unido participa plenamente). Pero, además, esta organización alcanza ámbitos materiales insospechados, debido al nivel de integración que se ha logrado, motivo por el cual la desconexión o retirada será una ardua tarea para el Estado que lo solicite (aspecto al que dedicaremos el siguiente epígrafe de este trabajo).

\section{La respuesta de la UE a las dudas británicas:}

la decisión política del Consejo Europeo de febrero de 2016

Antes de consumarse la promesa formulada por el premier británico en enero de 2013, ${ }^{24}$ David Cameron consiguió un gran logro materializado en el acuerdo en el seno del Consejo Europeo de febrero de 2016: la reinterpre-

23 Sobre el principio de primacía puede verse Díez-Hochleitner Rodríguez, Javier, "La aplicación judicial del derecho de la Unión Europea en España”, Anales de la Academia Matritense del Notariado, t. 50, 2010, pp. 33 y ss.

24 David Cameron prometió que si su partido ganaba las elecciones de mayo de 2015, en las que obtuvo mayoría absoluta, organizaría un referéndum sobre la permanencia en la Unión Europea antes de finalizar 2017. Disponible en: http: / /www.gov.uk/government/speeches leu-speech-at-blomberg. 
Esta revista forma parte del acervo de la Biblioteca Jurídica Virtual del Instituto de Investigaciones Jurídicas de la UNAM

tación de las disposiciones de derecho europeo predicables del Reino Unido, incorporadas en un extenso documento titulado "Un nuevo régimen para el Reino Unido en la Unión Europea”. ${ }^{25}$ Las negociaciones se iniciaron poco después de su reelección como primer ministro, con la idea de establecer un estatuto jurídico ventajoso para el Reino Unido, que respondiera a las inquietudes de los euroescépticos, de modo que se pudiera obtener un resultado holgado que beneficiara la posición del gobierno que pretendía su mantenimiento en la Unión. Sin embargo, este es un documento que ya no entrará en vigor, pues el inicio de su vigencia se hacía depender de una condición que no va a producirse: la confirmación británica al secretario general del Consejo Europeo de su decisión de permanecer en la UE. ${ }^{26}$

Cameron ordenó en cuatro grupos las que consideraba las principales preocupaciones respecto de la pertenencia de su país a la UE, a través de una carta remitida el 10 de noviembre de 2015 al presidente del Consejo Europeo, el polaco Donald Tusk. ${ }^{27}$ La respuesta llegó en los primeros días de febrero de 2016, en la carta del destinatario de la anterior a los miembros del Consejo, que contenía de forma sintética la propuesta de reinterpretación del estatuto británico. ${ }^{28}$ En ella se satisfacían las inquietudes transmitidas por David Cameron, alrededor de las cuatro rúbricas conforme a las cuales había vertebrado su misiva inicial que servían de estructura al plan elaborado con el horizonte del mantenimiento de la unidad de la Unión. Esos grupos se desarrollan de forma extensa en el documento antes apuntado, del que éste es un anuncio: la gobernanza económica, la competitividad, la soberanía y las prestaciones sociales y la libre circulación de personas.

En relación con el primer apartado, la gobernanza económica, el objetivo a lograr era "garantizar el respeto mutuo entre los Estados miembros que participan en la consolidación de la Unión Económica y Monetaria y aquellos que no lo hacen". ${ }^{29}$ No podemos evitar pensar que razonablemen-

25 El texto se encuentra en el Documento publicado de las Conclusiones del Consejo Europeo del 18 y 19 de febrero de 2016 y en Diario Oficial de la Unión Europea de 23 de febrero de 2016, núm. C 69, pp. 1 y ss.

26 Ibidem, sección E.2, en p. 9.

27 Cuyo contenido íntegro puede leerse en: https://www.gov.uk/government/publications / eu-reform-pms-letter-to-president-of-the-european-council-donald-tusk.

28 Véase el Comunicado de prensa en: http://www.consilium.europea.eu/es/press/pressreleases /2016/02/02-letter-tusk-proposal-new-settlement-uk/.

29 Véase en el documento indicado en la nota supra núm. 25, p. 1. 
Esta revista forma parte del acervo de la Biblioteca Jurídica Virtual del Instituto de Investigaciones Jurídicas de la UNAM

te la profundización de la Eurozona producida en los últimos años ha provocado, en palabras de Mercedes Guinea Llorente, una gran incomodidad al Reino Unido, debido a que cuenta con una importante industria financiera, y, en consecuencia, "tiene la legítima preocupación de no quedar marginado del núcleo duro de la decisión europea en estas áreas que pueden afectarle muy directamente". ${ }^{30}$ Por este motivo resulta necesario mantener el statu quo de cada uno de estos sectores con el propósito de evitar interferencias en uno u otro sentido, que es lo que establece el compromiso adoptado en febrero.

Por lo que se refiere a la competitividad, la pretensión subyacente a este grupo de propuestas supone fomentar un incremento de la misma ad intra y ad extra, de modo que se garantice las libertades de la Unión Europea. Araceli Mangas apunta en este sentido la profundización en "una integración ampliada a otros sectores y, por tanto, la expansión del mercado interior en servicios, energía, industria digital, etcétera, o a la aceleración de acuerdos con EEUU, Japón y la India, siempre que reúnan elementos equilibrados de reciprocidad, beneficio mutuo y adecuadas salvaguardias". ${ }^{31}$

Los dos últimos apartados eran el centro del interés particular del Reino Unido y el texto del Consejo Europeo incorpora diversos problemas en estos puntos. En cuanto a la soberanía, aparentemente la redacción es inocua y se limita a parafrasear el contenido del TUE. Pero lo interesante se encuentra en lo que rodea a esos recordatorios, al afirmarse en el documento que "se reconoce que el Reino Unido, habida cuenta de su situación específica conforme a los Tratados, no se ha comprometido a una mayor integración política en el seno de la Unión Europea”. ${ }^{32}$

Es evidente que el Reino Unido no comparte el modelo de progresividad que proclama elTUE, pero al ser parte en él se encuentra obligado por sus disposiciones, entre las que figura el compromiso de los Estados parte de lograr una Unión cada vez más estrecha. En consecuencia, la redacción delTratado indica precisamente lo contrario a lo que afirma el Consejo Europeo. Como señala Araceli Mangas, el contenido del precepto "aunque sea más filosófico que jurídico... no puede exonerar ahora del compromiso". ${ }^{33}$

30 Véase Guinea Llorente, Mercedes, "El Reino Unido y la renegociación de su estatuto de miembro de la Unión Europea”, Revista Aranzadi Unión Europea, núm. 4, 2016, pp. 63 y ss.

31 Véase Mangas Martín, Araceli, "Los dilemas del Reino Unido...”, cit., pp. 7 y ss.

32 Véase el Documento citado supra en nota núm. 25, p. 6.

33 Véase Mangas Martín, Araceli, "Los dilemas del Reino Unido...”, cit., p. 9. 
Esta revista forma parte del acervo de la Biblioteca Jurídica Virtual del Instituto de Investigaciones Jurídicas de la UNAM

Podrá cambiarse el texto del Tratado en una futura redacción, pero el derecho originario, del que el TUE forma parte, y que es a la UE lo que la Constitución es a los Estados, no se puede alterar sin aplicar el procedimiento de modificación oportuno que exige la unanimidad de los Estados miembros.

Además, en este punto se aborda el mantenimiento de la soberanía estatal por los Estados miembros que no es más que una reiteración de un principio sobradamente conocido: no han perdido soberanía como consecuencia de su integración en la Unión, sino que con fundamento en su soberanía han cedido el ejercicio de algunas de sus competencias. Esto nos conduce a una característica básica derivada de la soberanía funcional de las organizaciones internacionales: el principio de atribución de competencias proclamado en el TUE (artículo 5o.). Fruto de lo cual, de conformidad con el artículo 4.2 delTUE, la seguridad nacional se mantiene como competencia exclusiva de los Estados miembros, en lo que es una excepción a lo establecido en los tratados.

Sin embargo, el Consejo Europeo en su decisión viene a afirmar lo contrario al establecer que ello "no constituye una excepción al Derecho de la Unión y por consiguiente no deberá interpretarse en sentido restrictivo". ${ }^{34}$ Esto no afectaría de modo exclusivo al Reino Unido, ya que si el artículo 4.2 del TUE merece la lectura indicada por el Consejo Europeo será así para todos los Estados miembros, de lo que pueden derivar consecuencias insospechadas.

Un último elemento discutible incorporado en este punto sobre la soberanía es el referido al principio de subsidiariedad, ${ }^{35}$ pues pretende modificar las disposiciones contenidas en el tratado constitutivo (en concreto en el Protocolo núm. 2 sobre el principio de subsidiariedad y de proporcionalidad). Así, el documento del Consejo Europeo extiende en cuatro semanas las ocho que contiene el Protocolo para que los legislativos de los Estados miembros (artículo 6o.) remitan "un dictamen motivado que exponga las razones por las que considera que el proyecto no se ajusta al principio de subsidiariedad".

34 Documento citado supra en nota núm. 25, p. 7.

35 Principio que, de conformidad con el artículo 5.3 del TUE implica que, en cuestiones que no sean de su competencia exclusiva, la UE podrá adoptar un acto normativo exclusivamente cuando la actuación individual de los Estados miembros resulte insuficiente para alcanzar el propósito que se persigue, debido a la dimensión o a los efectos de la acción pretendida. 
Supone igualmente una modificación de los tratados en la medida en que omite u olvida que son dos requisitos cumulativos que establece el artículo 7.3 del mismo Protocolo para que el Consejo debata los dictámenes nacionales remitidos con fundamento en el principio de subsidiariedad, olvidando la intervención de la Comisión. ${ }^{36}$ Claro que los parlamentos nacionales y el Consejo estarán de acuerdo, no en vano es en el seno de los primeros donde se elige al gobierno estatal, por tanto, difícil será que no exista una posición acordada y lo que se refuerza en este punto es precisamente eso, la posición estatal. Volvemos a los localismos al ignorar a la Comisión que, no olvidemos, es quien defiende los intereses de la UE.

La última rúbrica es la relativa a las prestaciones sociales y libre circulación, que es también problemática, en la medida en que es uno de los aspectos que mayor relevancia ha tenido en la campaña del referéndum. Se establecen dos grandes apartados: uno, la interpretación de las normas de la $U E$ vigentes, y, otro, cambios en el derecho derivado de la UE. Es cierto que la libre circulación de trabajadores en el territorio europeo produce ventajas e inconvenientes, entre las primeras (ventajas) se encuentra la posibilidad de acudir a profesionales más allá del mercado nacional pudiendo reclutar trabajadores de los sectores productivos en otros lugares. De lo anterior se desprende el beneficio de incorporar personas capacitadas para sus desempeños laborales ahorrándose el Estado los costes derivados de su formación, como ha ocurrido en los últimos años en el sector sanitario en el Reino Unido.

Sin embargo, esa no es siempre la realidad de la libre circulación de trabajadores, pues existen reticencias por lo que se ha dado en denominar "turismo sanitario" o "turismo prestacional", entre otros. El sanitario sería aquel que practican ciudadanos de la UE para realizar determinados tratamientos médico-sanitarios no contemplados, por ejemplo, en el catálogo de prestaciones gratuitas de su Estado. Nos encontramos ante el turismo prestacional cuando ciudadanos de un Estado miembro acuden al territorio de otro en el que se goza de prestaciones no contributivas (ayudas de trans-

36 El artículo 7.3 establece ese requisito omitido en el documento del Consejo Europeo en su letra a) del siguiente modo: "antes de que concluya la primera lectura, el legislador (Parlamento Europeo y Consejo) estudiará la compatibilidad de la propuesta legislativa con el principio de subsidiariedad, atendiendo de forma particular a las motivaciones presentadas y compartidas por la mayoría de los Parlamentos nacionales y al dictamen motivado de la Comisión”. 
Esta revista forma parte del acervo de la Biblioteca Jurídica Virtual del Instituto de Investigaciones Jurídicas de la UNAM

porte, asignaciones por hijos o dependientes, subsidios por desempleo...). Este fenómeno, que ha afectado de modo subrayado a los quince primeros miembros de la UE a partir de la ampliación de 2004 y, especialmente, con la crisis económica más reciente, se ha presentado en la campaña británica como la causa de todos los problemas económicos del Reino Unido.

A pesar de todo, la situación actual no es consecuencia de las normas de la UE, que permiten restringir las prestaciones aludidas siempre que se respete lo establecido en la Directiva 2004/38, relativa al derecho de los ciudadanos de la Unión y de los miembros de sus familias a circular y residir libremente en el territorio de los Estados miembros. La norma permite limitar el derecho de residencia a quien disponga de "recursos suficientes para no convertirse en una carga para la asistencia social del Estado miembro de acogida durante su período de residencia, así como de un seguro de enfermedad que cubra todos los riesgos en el Estado miembro de acogida". ${ }^{37}$

Lo que no es posible, de conformidad con este acto de derecho derivado, es la expulsión de ciudadanos de la Unión Europea salvo que medien "motivos graves de orden público o seguridad pública". ${ }^{38}$ Por tanto, parte de las reivindicaciones británicas se pueden conseguir sin necesidad de modificar el derecho derivado, al preverse en el ordenamiento vigente. Sin embargo, el interés por complacer al Reino Unido va más allá y el Consejo Europeo ha decidido modificar la normativa actual en lo que afecta a la exportación de las prestaciones por hijos a un Estado distinto al de residencia del trabajador. En la misma se anuncia la modificación de un Reglamento, ${ }^{39}$ aunque

37 Es el artículo 7o. de la Directiva 2004/38/CE del Parlamento Europeo y del Consejo, del 29 de abril de 2004, relativa al derecho de los ciudadanos de la unión y de los miembros de sus familias a circular y residir libremente en el territorio de los Estados miembros por la que se modifica el Reglamento (CEE) núm. 1612/68 y se derogan las Directivas 64/221/ CEE, 68/360/CEE, 72/194/CEE, 73/148/CEE, 75/34/CEE, 75/35/CEE, 90/364/CEE, 90/365/CEE y 93/96/CEE, publicada oficialmente en Diario Oficial de la Unión Europea, del 30 de abril de 2004, núm. L158, pp. 77 y ss.

38 Es el artículo 28.2 de la Directiva citada en la nota anterior. No es la única ocasión en la que se establece la prohibición de expulsión de un ciudadano de la UE en este acto normativo comunitario.

39 En concreto, se trata del Reglamento 492/2011 del Parlamento Europeo y del Consejo, del 5 de abril de 2011 relativo a la libre circulación de los trabajadores dentro de la Unión, publicado oficialmente en Diario Oficial de la Unión Europea, del 27 de marzo de 2011, núm. L141, pp. 1 y ss. 
para ello es precisa la aplicación del procedimiento legislativo ordinario en el que el Parlamento, ausente en las reuniones que concluyeron con la adopción de este texto, es codecisor junto con el Consejo. ${ }^{40}$

De todo lo anterior se entiende claramente que el Consejo Europeo colaboró de forma sustantiva para que el resultado del referéndum celebrado fuera diferente al finalmente obtenido. Sin embargo, la realidad nos ha evitado observar las consecuencias de la vigencia de la Decisión en cuestión, no sólo respecto del Reino Unido, sino también en lo que se refiere a la aplicación generalizada de sus consideraciones.

\section{El rechazo del Reino Unido a la Unión Europea}

El referéndum realizado en Reino Unido el pasado 23 de junio produjo un resultado muy ajustado pues el $51.9 \%$ de los votantes apoyaron la salida frente al $48.1 \% .^{41}$ Datos que ilustran una sociedad muy dividida no sólo atendiendo al resultado, sino también al hecho de que la participación en la consulta (del 72.2\%) fue la más elevada tomando en consideración los procesos electorales desarrollados desde $1980 .{ }^{42}$

No podemos olvidar, en el momento de identificar algunos de los motivos que han impulsado a esa mayoría, los efectos de la crisis europea, crisis principalmente económica pero no exclusivamente con este alcance, dado que la respuesta de los líderes europeos a aquella ha producido otra serie de quiebras que han proporcionado un inmenso caldo de cultivo a los populismos. El recuerdo de otra época en crisis con regímenes populistas nos ha de golpear en la conciencia para que, con independencia de lo que ocurra, no vuelvan a repetirse las experiencias desoladoras experimentadas en otro tiempo no demasiado lejano. Jeffrey Sachs, por su parte, apuntaba que quienes votaron a favor del Brexit lo hicieron por una triple protesta:

40 El procedimiento legislativo ordinario se encuentra explicado y definido en los artículos 289 y 294 del TFUE.

${ }_{41}$ Resultados oficiales de The Electoral Commission, disponible en: http: / /www.electoralcommission.org.uk/find-information-by-subject/elections-and-referendums/past-elections-and-referen dums/eu-referendum/electorate-and-count-information.

42 Véase, entre otros, en: https://actualidad.rt.com/actualidad/211192-reino-unido-referen dum-resultados-brexit. 
Esta revista forma parte del acervo de la Biblioteca Jurídica Virtual del Instituto de Investigaciones Jurídicas de la UNAM www.juridicas.unam.mx

"Contra la oleada migratoria, contra los banqueros de la City londinense y contra las instituciones de la Unión Europea, en ese orden”. ${ }^{43}$

La sociedad británica, como otras europeas, cuenta con escasa movilidad social, de modo que las élites se caracterizan por la continuidad familiar mientras los menos favorecidos se mantienen en el lugar que tradicionalmente han ocupado. Si a esto añadimos que quienes han sufrido las medidas adoptadas para enfrentar la crisis económica han sido precisamente los indicados en último lugar, comprenderemos el motivo por el que los eslóganes de quienes hablan un lenguaje que entendemos y nos gusta escuchar suelen triunfar entre estos sectores sociales.

El desacierto del primer ministro Cameron en la realización del referéndum ha sido caracterizado por algún autor de "extremely irresponsible and myopic politics" ${ }^{44}$ A pesar de esto, las consultas populares son importantes y un elemento democrático innegable con dos matices: 1) cuando las repercusiones de la consulta afectarán a terceros, la lealtad implica la consulta y discusión de esta posibilidad con ellos; 2) quienes participan en las campañas defensoras de una opción u otra han de comportarse con responsabilidad, informando a los potenciales votantes de las ventajas y riesgos de apoyar la opción que defienden, lo que no ha sido el caso en el supuesto que nos ocupa, si tenemos en cuenta que, una vez conocido el resultado, algún líder defensor de la postura vencedora ha reconocido que las cifras sobre el beneficio económico que supondría para la población si se materializaba la retirada del Reino Unido de la Unión, no eran del todo ciertas. ${ }^{45}$ En todo caso, el Tesoro británico ha considerado que el Brexit implicará una reduc-

43 Véase Sachs, Jeffrey, “El significado del «Brexit»”, Tribuna de Opinión, El País, 26 de junio de 2016.

${ }_{44}$ Avbelj, Matej, "Brexit: An End to the End History", German Law Journal, vol. 17, Brexit supplement, 2016, p. 5.

45 Así, los 350 millones de euros semanales que, según los defensores del Brexit, costaba al Reino Unido su permanencia en la UE (véase en el diario El Confidencial, del 7 de julio de 2016). Es cierto que el Reino Unido es un contribuyente de la UE, según los datos oficiales, aporta el 0.52\% de su Renta Nacional Bruta, lo que supone 11,342 millones de euros y recibió de los fondos de la UE el equivalente a un $0.32 \%$ de la misma (6,985 millones de euros), la diferencia entre ambas cifras supone 4,357 millones de euros al año, según las cifras publicadas por la Unión Europea y que pueden comprobarse en http: / /europa.eu/about-eu/ countries/member-countries/unitedkingdom/index_es.htm. Sin embargo, el resultado semanal es de 83.79 millones de euros, que con ser una cantidad significativa, es menos del $24 \%$ de la cantidad esgrimida y reiterada por los defensores del Brexit. 
Esta revista forma parte del acervo de la Biblioteca Jurídica Virtual del Instituto de Investigaciones Jurídicas de la UNAM

ción de la renta de entre el 3.8 y el $9.5 \%$, dependiendo de cuál sea la relación establecida a posteriori con la UE. La OCDE, más optimista, reduce esa horquilla entre 2.72 y $7.7 \%$, pero descenso al fin y al cabo. ${ }^{46}$ La caída de la cotización de la libra esterlina a valores de hace treinta años en los días posteriores al referéndum evidencia la tendencia anterior. ${ }^{47}$

En una democracia representativa los poderes del Estado tienen el deber, siempre actuando dentro del ámbito de sus competencias, de adoptar decisiones en la medida en que la soberanía popular fundamenta su elección para guiar la política tanto en el orden interno como en el internacional. Tanto en el caso británico como en el caso español (artículo 92 de la Constitución), la celebración de una consulta popular tendrá exclusivamente naturaleza consultiva, ${ }^{48}$ a pesar de lo cual nadie puede dudar que si bien jurídicamente sería posible que un gobierno ignorara el resultado de un referéndum (debido a su naturaleza), esta opción resulta difícilmente planteable pues, desde una perspectiva política, su comportamiento contrario a la mayoría de la población expresada en las urnas resultaría insostenible. Richard Ekins, entiende que sería una opción injusta por cuanto:

It bears noting that the relatively powerless in our polity — the poor-overwhelmingly supported exit. Ignoring the referendum would be particularly unfair to them. It would not be consistent with treating them as free and equal persons entitled by the law and constitution of their land to a share in self-government, not least since the rationale for ignoring the process in which they participated has so often been framed in terms of outright contempt for them. Any failure to act on the decision made in the referendum that the UK should leave the $E U$ would be a profound betrayal. It would be no mere failure to recognize the perspective of the dispossessed, but would be the betrayal of holding out to them, as to others, a question for decision and then ignoring their decision because one does not like it. ${ }^{49}$

46 Véase Círculo Cívico de Opinión, "El Brexit y los intereses económicos españoles", Documento núm. 18, junio de 2016, p. 7, disponible en: http:www.circulocivicodeopinión.es.

47 Véase la reacción inmediata, entre otros medios, en: http://www.bbc.com/mundo/ noticias-internacional-36616058. La reacción subsiguiente puede leerse entre otros en: http: / / es.investing.com/fundamental / analisis/la-libra-esterlina-sigue-en-ca\%25C3\%25ADda-libre-7100.

48 Véase el European Union Referendum Act, de 2015, adoptado para esta consulta, en http: / / www.legislation.gov.uk/ukpga/2015/36/contents/enacted, y el Political Parties, Elections and Referendums Act, de 2000, en http://www.legislation.gov.uk/ukpga/2000/41/contents.

49 El texto transcrito puede leerse en la entrada del blog de Ekins, Richard, "The Legitimacy of the Brexit Referendum”, disponible en: https: / / ukconstitutionallaw.org/2016/06/29/ richard-ekins-the-legitimacy-of-the-brexit-referendum/. 
Esta revista forma parte del acervo de la Biblioteca Jurídica Virtual del Instituto de Investigaciones Jurídicas de la UNAM www.juridicas.unam.mx

Por su parte, Kenneth Rogoff, fundamenta su opinión contraria a la anterior en dos elementos: uno, el porcentaje del censo (que no de los votantes) que apoyó la salida del Reino Unido de la Unión Europea, que descendería hasta un 36\%, considerado insuficiente por el autor para decidir una cuestión tan relevante como la planteada; dos, el siguiente paso a dar para la desconexión es la solicitud del Parlamento en este sentido. Esto no sería problema si quienes defendieron el Brexit fueran mayoría en su seno, pero no es el caso. Llegados a este punto, se plantea si los parlamentarios deberán votar según su criterio o deberán adoptar como propio el resultado de un referéndum, aunque este posea exclusivamente naturaleza consultiva y sean contrarios a aquel. ${ }^{50} \mathrm{Si}$ se sienten obligados por el resultado del referéndum pueden estar traicionando la confianza depositada en ellos por sus electores. Si actuaran en conciencia estarían vulnerando el sentir mayoritario expresado en las urnas.

Un apartado que no podemos olvidar en este capítulo son las posibles causas del rechazo a la UE. En este sentido, la profesora Mangas apunta uno clarísimo: la falta de pedagogía por parte de las autoridades británicas a la hora de explicar, entre otras cuestiones, lo que supone la libre circulación de trabajadores. ${ }^{51}$ Ciertamente, en el territorio de la UE los nacionales de los Estados miembros son titulares del derecho de libre circulación, ${ }^{52}$ por tanto, aunque son extranjeros no se consideran inmigrantes.

El estatuto de ciudadano de la Unión implica que en todos los Estados miembros se ha de tratar a los nacionales de los demás Estados como a los propios nacionales, siempre que se reúnan los requisitos para ello. ${ }^{53}$ Eso quiere decir que, por ejemplo, los británicos residentes en España ${ }^{54}$ son

50 Véase Rogoff, Kenneth, "Britain's Democratic Failure”, https://www.project-syndicate. org/commentary/brexit-democratic-failure-for-uk-by-kenneth-rogoff-2016-06.

51 Véase Mangas Martín, Araceli, “Sorprendente caja de Pandora británica”, Opinión, El Mundo, 30 de junio de 2016.

52 Con fundamento en el artículo 3.2 del TUE, del artículo 21 del TFUE y de los títulos IV y V de este último y desarrollados en la Directiva 2004/38/CE, relativa al derecho de los ciudadanos de la Unión y de los miembros de sus familias a circular y residir libremente en el territorio de los Estados miembros. Véase Diario Oficial de la Unión Europea, núm. L 158, del 30 de abril de 2004, pp. 77 y ss.

53 Así lo ha puesto de relieve el Tribunal de Justicia de la Unión Europea en las sentencias del 11 de noviembre de 2014, en el asunto Dano C-333/13 y del 15 de septiembre de 2015, en el asunto Alimanovic C-67/14.

54 Se calcula que hay aproximadamente dos millones de nacionales del Reino Unido viviendo en el territorio de los veintisiete Estados miembros de la UE, según el informe HM 
Esta revista forma parte del acervo de la Biblioteca Jurídica Virtual del Instituto de Investigaciones Jurídicas de la UNAM

titulares del derecho de sufragio activo y pasivo en las elecciones municipales, cuentan con los derechos sanitarios con un alcance exactamente igual al de los españoles, sus hijos tienen plaza en los colegios públicos o las universidades, en este último caso abonando las tasas correspondientes a los nacionales de la UE, participan de los subsidios existentes en materia de desempleo, vivienda, transporte y cualesquiera otros de los que se puedan beneficiar los nacionales. Lo mismo sucede con los españoles (y nacionales de los demás Estados miembros) residentes en el Reino Unido.

Los partidarios del Brexit han utilizado el elemento anti-inmigración como un importante eje en la defensa de sus intereses. Al calor de este discurso, los brotes de xenofobia, más propios de tiempos pasados que deberíamos haber superado, han aumentado considerablemente en el Reino Unido, ${ }^{55}$ de modo particular en contra de ciudadanos polacos. Sin embargo, hay que tener en cuenta que si bien el Brexit puede terminar con la libre circulación de ciudadanos de la Unión Europea en territorio del Reino Unido y viceversa, ello no afecta a los derechos adquiridos por quienes residan o tengan sus negocios en uno y otro lugar. La seguridad jurídica motiva esta disposición incorporada en la Convención de Viena sobre el Derecho de los Tratados ${ }^{56}$ sin perjuicio del acuerdo contrario de las partes. Por tanto, podrán, una vez que entre en vigor el acuerdo de desconexión, evitar las llegadas de ciudadanos de la UE, pero no expulsar a quienes ya están radicados allí.

Lo anterior nos conduce al crecimiento de los populismos en el Reino Unido, transformados en localistas y alejados de los objetivos comunes que prenden en el continente europeo. No es de extrañar que otros líderes de formaciones de extrema derecha igualmente populistas se hayan congratu-

Government, "The Process for withdrawing from the European Union”, p. 17, parágrafo 4.2, disponible en: https: / / www.gov.uk/government/uploads/system/uploads/attachment_data/fi le/503908/54 538_EU_Series_No2_Accessible.pdf.

55 El diario El Mundo informaba acerca del incremento en un 54\% de los incidentes de racismo, de conformidad con un informe policial. Véase en Fresneda, Carlos, "Los episodios de xenofobia se disparan tras la victoria del brexit”, El Mundo, 30 de junio de 2016.

56 El artículo 70 de la citada Convención, en relación con las consecuencias de la terminación de un tratado internacional establece: "1. Salvo que el tratado disponga o las partes convengan otra cosa al respecto, la terminación de un tratado en virtud de sus disposiciones o conforme a la presente Convención: a) eximirá a las partes de la obligación de seguir cumpliendo el tratado; b) no afectará a ningún derecho, obligación o situación jurídica de las partes creados por la ejecución del tratado antes de su terminación”. 
Esta revista forma parte del acervo de la Biblioteca Jurídica Virtual del Instituto de Investigaciones Jurídicas de la UNAM

lado del resultado de la consulta británica, como Marine Le Pen. ${ }^{57}$ La situación europea de crisis económica y descrédito de los partidos tradicionales es buen caldo de cultivo para grupos que utilizan mensajes muy simples y xenófobos, de rápido calado en las clases medias y bajas, que observan con desesperanza el negro horizonte que les dibuja una crisis económica que no han contribuido a crear pero cuyas consecuencias están sufriendo. ${ }^{58}$

Por otra parte, los partidarios de la permanencia en la UE, siendo más moderados políticamente, no han omitido lanzar mensajes de difícil digestión. Hay quienes han apuntado como responsables de la opción vencedora a las personas de mayor edad y a las de menor formación académica. Por este motivo, se han lanzado campañas para limitar el ejercicio del derecho de sufragio de forma claramente discriminatoria a las personas de mayor edad, motivando que la Experta de Naciones Unidas sobre el disfrute de todos los derechos humanos de las personas mayores se haya pronunciado ${ }^{59}$ deplorando esta ola de ataques. Por otra parte, dispuestos a establecer un sufragio censitario siempre podemos limitar el ejercicio de este derecho por razón de edad, de formación, de clase social... predeterminando los resultados electorales en función del sector titular del sufragio. Pero convengamos que, por muy flexible que resulte nuestro concepto de democracia, esta práctica no se ve alcanzada por este.

\section{CONSECUENCIAS DEL BREXIT}

La primera consecuencia que se ha evidenciado en la campaña del Brexit y en los momentos posteriores al referéndum es una quiebra, una fractura social y también territorial, que se aprecia especialmente bien en Escocia. Uno de

57 Existen múltiples evidencias de este apoyo, entre ellas puede indicarse la noticia publicada en http:/ / elpais.com/elpais/2016/06/26/opinion/1466953635_514285.html.

58 Véase una reflexión en este sentido en las páginas de la prensa nacional e internacional, por ejemplo, en: http://internacional.elpais.com/internacional/2016/06/24/actualidad/14 66747683_421802.html.

59 La experta transmitía la alerta que le producían las numerosas voces que en el Reino Unido se habían levantado para limitar la edad en el ejercicio del derecho de sufragio, lo que claramente es una restricción de los derechos políticos discriminatoria por razón de edad, disponible en: http: / / www.ohchr.org/EN/NewsEvents/Pages/DisplayNews.aspx? NewsID=20241\&LangID=E . 
los elementos clave que animaron a los escoceses a mantenerse dentro del Reino Unido en el referéndum desarrollado el 18 de septiembre de 2014 fue precisamente que no podrían continuar en el estatuto de parte de la UE de prosperar la opción independentista, pues Escocia tendría que solicitar la admisión a esta organización que sólo se resuelve por unanimidad de los Estados miembros. También se ha producido quiebra de los partidos políticos tradicionales, ${ }^{60}$ ya que ni las filas de los laboristas ni las de los conservadores han estado unidas en este punto; entre otras posibles fracturas que podemos identificar. Sin embargo, nuestro propósito en este trabajo es intentar visualizar las consecuencias que desde la perspectiva de la Unión Europea se pueden derivar de la situación actual.

En las páginas que siguen vamos a centrar nuestras reflexiones en dos aspectos concretos: en primer lugar, el modelo de relaciones que se van a desarrollar entre la UE y el Reino Unido una vez concluido el proceso de desconexión; en segundo término, algunos ámbitos materiales concretos que se verán afectados y deberán ser resueltos también en función del modelo relacional adoptado.

\section{Primeras dudas a resolver: el modelo de relaciones futuras entre el Reino Unido y la Unión Europea}

Las consecuencias de la retirada de un sistema económico y comercial fuertemente integrado en el que el Reino Unido ha permanecido durante cuarenta y tres años distan mucho de ser fácilmente identificables. La vuelta a la situación anterior resulta de una complejidad alejada de la simple pregunta a la que tuvo que responder la ciudadanía británica el pasado 23 de junio. Es evidente que el Reino Unido no es el mismo que hace casi medio siglo y que el resto del mundo también ha evolucionado. Lo primero que habría que resolver es el escenario en el que nos encontraremos en el momento en que concluyan las negociaciones a las que nos conduce la aplicación del artículo 50 delTUE. En este sentido, Araceli Mangas plantea un abanico de posibilidades para un futuro no muy lejano:

60 Véase un desarrollo de esta idea en Ortega, Andrés, “¿ «Arrepentexit», o retraso indefinido?”, disponible en: http: / / www.blog.rielcano.org/arrepentexit-o-retraso-indefinido/. 
Esta revista forma parte del acervo de la Biblioteca Jurídica Virtual del Instituto de Investigaciones Jurídicas de la UNAM www.juridicas.unam.mx

1) Negociar un acuerdo de retirada con una relación privilegiada o no; 2) Integrarse en el Espacio Económico Europeo (como Noruega, aceptar las normas sin participar en su adopción); 3) Integrarse con la EFTA (regreso a 1960); 4) modelo suizo con cientos de acuerdos sin acceso a los servicios y la City cortocicuitada; 5) Negociar un acuerdo de libre comercio con la UE; 6) Negociar una Unión Aduanera (como Turquía) sin acceso al mercado interior; 7) Limitar sus relaciones a las reglas de la OMC (el trato dado a Rusia, China...). ${ }^{61}$

Sólo el tiempo nos dirá en cuál de ellos nos ubicaremos, pues dependerá del acuerdo con el que se concluyan las negociaciones que, según David Davis, actual secretario del Brexit, podrían comenzar a finales de 2016 o a principios de 2017 y concluirán en diciembre de 2018. Sí conocemos cuáles son los modelos preferidos por el Reino Unido: serán los que le permitan participar en el mercado interior como el resto de los Estados miembros, pero excluyendo una de sus libertades fundamentales: la libre circulación de personas. Una pretensión que, a la luz de lo declarado por el Consejo de Asuntos Generales de diciembre de 2014, no parece viable, dado que "the free movement of persons is a fundamental pillar of EU policy and that the internal market and its four freedoms are indivisible". ${ }^{62}$

Además, el Reino Unido se deberá asegurar el acceso preferencial al mercado de la UE en sectores en los que tiene un especial interés por mantener la situación actual, como los servicios financieros (debido a la relevancia de la City londinense) y del sector automovilístico. ${ }^{63}$

El sector financiero de Londres es el mayor del mundo, ${ }^{64}$ en esta ciudad se encuentran más de doscientos cincuenta bancos extranjeros con acceso al mercado único y con él a la libre circulación de capitales debido a que el Reino Unido es miembro de la Unión Europea. Según Sajjad Karim, "It also accounts for $10 \%$ of the nation's GDP, $12 \%$ of the treasury's tax receipts, and is the

61 Mangas Martín, Araceli, "Referéndum sobre la permanencia del Reino Unido en la UE: consecuencias”, Cuadernos del Círculo cívico de opinión, núm. 18, junio de 2016, p. 15.

62 Conclusiones del Consejo de Asuntos Generales sobre un mercado único homogéneo y las relaciones de la UE con los países de Europa Occidental no pertenecientes a la UE, reunido en Bruselas, 16 de diciembre de 2014, parágrafo 45, p. 7, disponible en: http: / / www. consilium.europa.eu/es/meetings/gac/2014/12/16/.

63 Id. nota supra núm. 54, parágrafo 4.3, p. 17.

64 Sobre la relevancia de la City en el Reino Unido, véase Titos, Enrique, "El impacto del Brexit en la prestación de servicios financieros por el Reino Unido", Fundación para la Investigación sobre el Derecho y la Empresa (FIDE), http: / /www.fidefundacion.es. 
Esta revista forma parte del acervo de la Biblioteca Jurídica Virtual del Instituto de Investigaciones Jurídicas de la UNAM

largest exporter of wholesale financial services in the world. The sector employs over a million workers across the country, and contributes significantly to secondary jobs in the economy". ${ }^{65}$

No podemos obviar tampoco las palabras de Araceli Mangas, quien afirma que "el gran perdedor del proceso sería el poderoso sector financiero británico, la City, en lenguaje coloquial. La nueva etapa abriría un proceso de cambio en el sector, con elevada incertidumbre y hasta posibles relocalizaciones empresariales" ${ }^{66}$

Todo indica que es un sector al que le interesa mantenerse dentro del mercado común para conservar la relevancia que posee en la actualidad. Según el informe del gobierno británico, la desconexión del Reino Unido de la UE suscita dos problemas en este punto. El primero es el relativo al estatuto de las firmas británicas "whose existing business operations in other $E U$ Member States were authorized under EU law, and of firms based in other EU Member States with operations in the UK" ${ }^{67}$

El segundo se refiere a la aplicación de la legislación interna que, en la actualidad, es derecho de la UE, pues el sector se encuentra regulado por normas de transposición de Directivas europeas. La preocupación aquí radica en el hecho que "the UK Government would be how to avoid regulatory gaps in the UK's domestic legislative framework once the EU Treaties ceased to apply. This would involve questions over how existing EU law could or should be adopted into domestic law". ${ }^{68}$

Problemas que deberán resolverse en los próximos dos años, en todo caso, mientras eso acontece, al sector de los servicios financieros (tan relevante para la economía británica) ya le están saliendo novios, pues ante la eventual vacante que dejaría la salida del Reino Unido de la UE y con ella de la City londinense, se están postulando ciudades como Madrid, París o Frankfurt, entre otras, que ya han emprendido la carrera para convertirse en la nueva City.

65 Véase Karim, Sajjad, "Brexit will destroy the City of London as we know it", disponible en: https: / / www.euractiv.com/section/uk-europe/opinion/brexit-will-destroy-the-city-of-london-aswe-know-it/.

66 Mangas Martín, Araceli, "Referéndum sobre la permanencia...”, cit., p. 8.

67 Véase en la p. 17 del Informe del Gobierno del Reino Unido en: https://www.gov.uk/ government/publications/the-process-for-withdrawing-from-the-european-union.

68 Idem. 
Esta revista forma parte del acervo de la Biblioteca Jurídica Virtual del Instituto de Investigaciones Jurídicas de la UNAM

De los modelos antes referidos por la profesora Mangas, sin duda el más interesante para el Reino Unido consiste lograr un acuerdo privilegiado con la UE, que sea un traje a la medida de sus intereses. Jurídicamente esta elección es posible pero políticamente sería un error si la UE se quiere mantener con el mayor número de los miembros actuales posibles. Ya se comienza a hablar de Nexit, en alusión a la salida de los Países Bajos, y también de Polonia o de Hungría, que podrían considerar mejor satisfechos sus propósitos siguiendo el eventual modelo británico que manteniendo su estatuto de miembros de la UE.

También el modelo noruego ${ }^{69}$ permitiría al Reino Unido participar en el mercado interior, aunque ello supondría (si se mantiene lo establecido por el Consejo de Asuntos Generales de diciembre de 2014) el mantenimiento de la libre circulación de personas en contra de los deseos expresados por el Reino Unido. En todo caso, la membresía en el Espacio Económico Europeo presenta un déficit respecto del estatuto de miembro de la UE: permite participar del mercado pero no de la creación normativa de las reglas que ordenan aquel. En consecuencia, el Reino Unido tendría una posición debilitada respecto de la actual.

Otros autores, como Jacqueline Breidlid y Cenni Najy, entienden que el modelo suizo es el más probable para resolver la futura relación entre la Unión Europea y el Reino Unido. Recordemos que Suiza articula su relación con la UE a través de tratados bilaterales ${ }^{70} \mathrm{e}$ incorpora unilateralmente y a su conveniencia la aplicación en su territorio de las normas europeas que le interesan. Sin embargo, este modelo no deja de suscitar inconvenientes que nos hacen dudar de su concreción en el caso británico. ${ }^{71}$ En primer lugar, ha de señalarse la extensión temporal que supuso la celebración de los tratados bilaterales en el caso suizo, que requirieron alrededor de diez

69 Además de Noruega, es el modelo de relaciones con la UE que mantienen Liechtenstein e Islandia: el Espacio Económico Europeo, vigente desde el 1o. de enero de 1994, que permitió a los tres países acceder al mercado interior de la Unión con todas sus libertades, pero sin tener que adherirse a ella.

70 Más de cien en la actualidad. Puede encontrarse un panorama de las relaciones comerciales entre Suiza y la UE en http: / / ec.europa.eu/trade/policy/countries-and-regions/coun tries/switzerland/. En paralelo, Suiza forma parte de la Asociación Europea de Libre Comercio.

71 Véase Breidlid, Jacqueline y Najy, Cinni, "Plan B after Brexit. What Britain can expect negotiating a Swiss-Type arrangement with the EU”, Foraus-Swiss Forum on Foreign Policy, Policy Brief, junio de 2016. 
Esta revista forma parte del acervo de la Biblioteca Jurídica Virtual del Instituto de Investigaciones Jurídicas de la UNAM

años. ${ }^{72}$ Es cierto que con el Reino Unido los plazos podrían ser más cortos atendiendo a su pertenencia a la UE, pero no deja de ser un aspecto a tener en cuenta. En segundo lugar, se deben considerar los costes de la relación, que tampoco ha resultado gratis, pues "la Suisse a déboursé plusieurs milliards d'euros pour maintenir ces accords (principalement sous la forme d'une contribution de solidarité à destination des pays les moins favorisés de l'UE)". ${ }^{73}$

El tercero de los problemas derivados de este modelo, que ya conocíamos del modelo noruego, es que Suiza carece de capacidad de decisión normativa. Ni siquiera cuenta con ella en relación con los actos que encuentran fundamento en los Acuerdos de Schengen, de los que Suiza sí que es parte, pues si bien en las reuniones del Consejo participa su ministro de asuntos exteriores lo hace careciendo de derecho de voto. ${ }^{74}$

Las palabras de Thierry Chopin y Jean-François Jamet ilustran cuanto hemos expresado hasta aquí. El Reino Unido y la UE tendrán que decidir la modalidad aplicable a sus relaciones futuras, pero el Reino Unido ha de ser consciente de que "none of these various options is deemed totally satisfactory by the British government since the UK would certainly continue to take part in the internal market but would lose the greater share of its ability to influence the rules, as it would no longer be taking part in the vote for their approval". ${ }^{75}$

El gobierno británico, antes del referéndum, ya elaboró un informe acerca de los modelos relacionales en caso de que triunfara la opción de la retirada de la Unión Europea, con las ventajas e inconvenientes de cada uno de ellos. ${ }^{76}$ En todo caso, la invocación del artículo 50 del TUE (cuando se produzca) no implicará automáticamente la recuperación del ejercicio de competencias cedido a la UE, lo que sólo se producirá cuando el acuerdo en el que se establezcan las condiciones de retirada entre en vigor y exclusivamente en cumplimiento de lo allí establecido. Por tanto, mientras no

72 Ibidem, p. III.

73 Ibidem, p. IV.

74 Sin embargo, los suizos también desean evolucionar en sus relaciones con la UE, para establecer una "asociación” que le permita distinguirse de otros Estados no miembros. Véase, en este sentido, Rochel, Johan, “La Suisse et l'Union européenne: Pour une association active et flexible”, Foraus-Forum de politique étrangere, Papier de discussion núm. 29/Juin 2016.

75 Véase en Chopin, Thierry y Jamet, Jean-François, “After de UK's EU referéndum: redefining relations between the «two Europes»", European issues, Fondation Robert Schuman, núm. 399, 5 de julio de 2016, p. 2.

76 Véase en https://www.gov.uk/government/publications/the-process-for-withdrawing-from-the -european-union. 
Esta revista forma parte del acervo de la Biblioteca Jurídica Virtual del Instituto de Investigaciones Jurídicas de la UNAM

llegue ese momento, la situación se mantiene tal cual era, el Reino Unido sigue siendo miembro de la Unión y ello supone la imposibilidad siquiera de iniciar a tejer las relaciones que eventualmente puedan sustituir las existentes dentro de la Organización, hasta que haya recuperado las competencias que le habilitan para ello, lo que se producirá cuando termine su estatuto de miembro, no antes.

\section{Algunos ámbitos materiales afectados por el Brexit}

A pesar de las incertidumbres que rodean este periodo en el que nos encontramos inmersos, podemos intuir las materias que se verán más afectadas por esta nueva situación, a las que nos vamos a referir en las páginas siguientes. Por motivos de extensión, nos vemos obligados a hacer una selección que habrá de servir como muestra de otros muchos ámbitos que podrían verse afectados por el Brexit (y seguramente así suceda). Nos centraremos en primer lugar en la acción exterior, concediendo un papel destacado a la política comercial. Continuando con la relevancia del comercio, nos referiremos al eventual impacto del Brexit en la normativa sobre procedimientos concursales y en la regulación de los mercados financieros, de los cuales Londres es un epicentro. Por último, analizaremos los efectos que la salida británica de la UE podrá tener en la política de seguridad y defensa, incluyendo la lucha contra el terrorismo.

Comencemos con la acción exterior, vertebrada en la actualidad por una multiplicidad de acuerdos entre la Unión y terceros Estados, tejidos a lo largo de decenios, que son el reflejo de las competencias exclusivas de la Organización. ${ }^{77}$ Competencias exclusivas que se traducen en la imposibilidad de acción estatal, debido a la cesión de su ejercicio en beneficio de la UE. Por este motivo, la desconexión pasa por un doble trabajo: por una parte, de la propia Unión Europea para negociar su nueva posición sin el

77 Obsérvese en este punto el artículo 3o. delTFUE, que indica los ámbitos de competencia exclusiva de la UE: “a) la unión aduanera; b) el establecimiento de las normas sobre competencia necesarias para el funcionamiento del mercado interior; c) la política monetaria de los Estados miembros cuya moneda es el euro; d) la conservación de los recursos biológicos marinos dentro de la política pesquera común; e) la política comercial común”. Por su parte, el artículo 4o. enuncia los ámbitos materiales objeto de competencia compartida, que pueden haber sido ocupados plenamente (o no) por la UE. 
Esta revista forma parte del acervo de la Biblioteca Jurídica Virtual del Instituto de Investigaciones Jurídicas de la UNAM

Reino Unido; por otra, de este último que tendrá que ubicarse de nuevo en la escena internacional, negociando sin la fuerza que le supone tener detrás a otros 27 Estados y que ofrece un mercado potencial de menor interés para las eventuales contrapartes del que presentaba en un momento anterior, ${ }^{78}$ lo que le producirá menores beneficios.

Es evidente que el mundo ha cambiado mucho en los cuarenta y tres años que ha permanecido la membresía del Reino Unido en la UE. Recuperar los tratados internacionales que vertebraban las competencias tanto comerciales - hoy cubiertas por la política comercial común - como exteriores, cuyo ejercicio ha sido cedido a la Unión Europea durante casi medio siglo, es impensable, precisamente debido a la rápida evolución sufrida. En este sentido, Corinne Deloy afirma que "it will no longer be able to take advantage of the single market and it will have to renegotiate all of the trade relations it has, with the EU and with all of the States linked to the latter by a treaty". ${ }^{79}$

El Reino Unido no sólo tendrá que renegociar sus relaciones con la UE, lo que se resolverá en los próximos meses, sino también con el resto de los Estados con los que desee mantener relaciones comerciales o de otro tipo al margen de la organización en la que goza aún en la actualidad del estatuto de miembro. Si el divorcio fuera amistoso - lo que parece desprenderse de la Declaración de Bruselas del 29 de junio de 2016 —, ${ }^{80}$ las instituciones de la Unión podrían, no obstante, sobre la base habilitadora que le proporciona el artículo 207.2 del TFUE, adoptar un reglamento que permita al Reino Unido la celebración de acuerdos comerciales con el propósito de facilitarle sus futuras relaciones mercantiles. ${ }^{81}$ Esto es muy importante, porque se calcula que habrá de negociar alrededor de doscientos

78 Véase Mangas Martín, Araceli, “Referéndum sobre la permanencia...”, cit., pp. 15-17.

79 Deloy, Corinne, "Supporters and Adversaries to the UK Remaining in the European Union are Running Neck and Neck in the Polls Just One Month Before the Referéndum”, Political Issues. Referendum in United Kingdom, Fondation Robert Schuman, pp. 1 y 2.

80 En la Declaración de los veintisiete, cuya referencia completa se incorpora en la nota siguiente, se establece en el apartado segundo la necesidad "de organizar la retirada del Reino Unido de manera ordenada”. Cierto es que de esta frase puede razonablemente desprenderse lo indicado en el texto principal u otro contenido diverso, en la medida en que el concepto de orden no afecte tanto al Estado que abandona como a la organización abandonada.

81 Así lo establecieron los jefes de Estado y de gobierno en el apartado primero de la Declaración acordada en la reunión informal de los veintisiete, celebrada el 29 de junio de 2016 en Bruselas. También en Delgado Casteleiro, Andrés, "Brexit, el artículo 50 TUE y la repatriación de la política comercial”, Fundación para la Investigación sobre el Derecho y 
Esta revista forma parte del acervo de la Biblioteca Jurídica Virtual del Instituto de Investigaciones Jurídicas de la UNAM

acuerdos de comercio que reemplazen las ochenta mil páginas de normas adoptadas por la UE y "nothing was planned for in the European treaties for the specific period of whithdawal by a Member States, wich could therefore last several years". ${ }^{82}$

Sin abandonar el ámbito mercantil, la desconexión del Reino Unido de la Unión Europea también tendrá sus implicaciones en el derecho privado y procesal. Como indica Ángel Carrasco Perera, los procedimientos de insolvencia se encuentran regulados por el derecho de la UE, en virtud de una interpretación creativa de sus disposiciones los jueces y abogados londinenses imponen procedimientos preinsolvencia aun cuando el centro de intereses del deudor no se encuentra dentro del alcance de la jurisdicción británica. ${ }^{83}$ Consumado el Brexit esto ya no será posible porque esta cuestión pasará a regirse por normas británicas y no resultará de aplicación el Reglamento en cuestión. La relevancia de Londres como plaza judicial y, en concreto, como centro privilegiado de solución de litigios, es innegable y es otra cuestión en la que habremos de estudiar si afectará o no el Brexit. El alcance de la incidencia de la retirada del Reino Unido de la Unión Europea en este ámbito material puede resultar intenso especialmente teniendo en cuenta que el Reino Unido será un Estado tercero que no se beneficiará de las disposiciones del Reglamento relativo a los mercados de instrumentos financieros, ${ }^{84}$ que establece, en relación con las empresas de Estados no miembros, lo siguiente:

Las empresas de terceros países... ofrecerán a los clientes establecidos en la Unión, antes de la prestación de cualquier servicio o realización de cualquier actividad, la posibilidad de someter toda eventual controversia relacionada con dichos servicios

la Empresa, disponible en: http: / / www.fidefundacion.es/Brexit-El-Articulo-50-TUE-y-la-repatria cion-de-la-politica-comercial_a367.html.

82 Deloy, Corinne, “Supporters and adversaries...", cit., pp. 6 y 7.

83 Véase Carrasco Perera, Angel, “«Brexit» y algunos bonitos problemas jurídicos que acarrearía la salida británica de la Unión Europea”, Actualidad Jurídica Aranzadi, núm. 918/2016, del 4 de julio de 2016. Se refiere al Reglamento (UE) 2015/848 del Parlamento Europeo y del Consejo, del 20 de mayo de 2015, sobre procedimientos de insolvencia, publicado oficialmente en Diario Oficial de la Unión Europea, núm. L173, del 12 de junio de 2014, pp. 84 y ss.

84 Se trata del Reglamento (UE) núm. 600/2014 del Parlamento Europeo y del Consejo, del 15 de mayo de 2014, relativo a los mercados de instrumentos financieros y por el que se modifica el Reglamento (UE) núm. 648/2012, publicado oficialmente en Diario Oficial de la Unión Europea, núm. L173, de 12 de junio de 2014, p. 84 y ss. 
Esta revista forma parte del acervo de la Biblioteca Jurídica Virtual del Instituto de Investigaciones Jurídicas de la UNAM

o actividades a la jurisdicción de un tribunal o de un tribunal de arbitraje de un Estado miembro. ${ }^{85}$

Además, la Directiva sobre mercados de instrumentos financieros indica:

Los Estados miembros podrán exigir que las empresas de terceros países que se propongan prestar servicios de inversión o realizar actividades de inversión, con o sin servicios auxiliares, para clientes minoristas o para clientes profesionales en el sentido del anexo II, sección II, en su territorio establezcan una sucursal en el Estado miembro de que se trate. ${ }^{86}$

De acuerdo con la interpretación aportada por Burkhard Hess y Marta Requejo, las disposiciones anteriores se traducen en que "un contrato cerrado hoy que establezca Londres como lugar de resolución de la disputa no puede garantizar que la cláusula de elección del foro tendrá validez dentro de dos años". ${ }^{87}$

Por tanto, el consejo evidente es que se eviten este tipo de cláusulas, con lo que Londres perderá también la relevancia que tiene como plaza de resolución de litigios, con la consiguiente repercusión sobre su economía. En consecuencia, otras ciudades europeas se postularán para sustituir a la capital británica.

Otro ámbito interesante es el relativo a la Política Europea de Seguridad y Defensa (PESD) ${ }^{88}$ en el que el Brexit también va a tener sus implicaciones. El Reino Unido cuenta con una relevancia sustantiva en la defensa europea, pues de acuerdo con Shaun Riordan, "los únicos con una capacidad para desplegarse en el exterior son los británicos y franceses, que también son los únicos poderes nucleares europeos y representantes permanentes

85 Es el artículo 46.6 del texto indicado en la nota anterior.

86 El texto transcrito es el artículo 39.1 de la Directiva 2014/65/UE del Parlamento Europeo y del Consejo, del 15 de mayo de 2014 relativa a los mercados de instrumentos financieros y por la que se modifican la Directiva 2002/92/CE y la Directiva 2011/61/UE, publicado oficialmente en Diario Oficial de la Unión Europea, núm. 173, del 12 de junio de 2014, pp. 349 y ss.

87 Hess, Burkhard y Requejo Isidro, Marta, "Brexit: las consecuencias sobre Londres como plaza judicial”, la versión inglesa se encuentra en Kluwer Arbitration Blog, http: / kluwerarbitrationblog.com/; la española en el de Aquiescencia, https: / / aquiescencia.net/.

88 Véase Arteaga, Félix, “Brexit me, Brexit me mucho...”, Real Instituto Elcano, disponible en: http: / / www.blog.rielcano.org/brexit-me-brexit-me-mucho. 
Esta revista forma parte del acervo de la Biblioteca Jurídica Virtual del Instituto de Investigaciones Jurídicas de la UNAM

europeos en el Consejo de Seguridad de la ONU”. ${ }^{89}$ En consecuencia, la presencia de la UE en el Consejo quedará reducida a la mitad.

Siguiendo con lo anterior, es posible que de la salida del Reino Unido se derive una mayor dependencia defensiva de Europa respecto de la OTAN para paliar su ausencia. No obstante, conviene relativizar esta hipótesis a la vista de que ya en los últimos años la participación del Reino Unido en operaciones defensivas se ha reducido a zonas de su interés para el Estado, no siempre coincidente con el de la Unión Europea.

Continuando con las relaciones transatlánticas, la relación con Estados Unidos también puede verse afectada, ya que el Reino Unido venía de algún modo defendiendo o presentando en el seno de la Unión Europea los valores anglosajones que comparten con su socio norteamericano. Por otra parte, un vértice importante de la relación defensiva con Estados Unidos se encuentra en el hecho de que Reino Unido ha sido su gran aliado militar, lo que en un futuro a medio plazo puede quedar en el aire, debido a la reducción del gasto en materia de defensa que ha sido anunciada por el presidente Cameron. ${ }^{90}$

No podemos olvidar, al hilo de lo anterior, el problema del terrorismo internacional al que Europa debe hacer frente. Este fenómeno afecta de manera singular al Reino Unido, de acuerdo con los datos que manejan Fernando Reinares y Carola García-Calvo, según los cuales a finales de 2015 del Reino Unido habían salido con destino a Siria e Iraq unos ochocientos combatientes nacionales británicos o residentes en su territorio. De ellos, casi la mitad habían regresado al país. Por otra parte, gracias a los servicios de inteligencia y a los sistemas de información europeos se pudieron evitar casi una decena de atentados en su territorio. ${ }^{91}$ Pero la salida del Reino Unido también podría tener efectos en la otra dirección, haciendo peligrar la colaboración de la inteligencia británica (uno de los "cinco ojos", junto con Estados Unidos, Nueva Zelanda, Australia y Canadá) con los restantes Estados miembros.

89 Véase Riordan, Shaun, “"Brexit»: implicaciones para la seguridad europea”, Instituto Español de Estudios Estratégicos, Documento de opinión, 63bis/2016, del 23 de junio de 2016, p. 9.

90 Montoya Cerio, Fernando, “"Brexit» ficción o realidad: impacto sobre la PESCD de la UE”, Instituto Español de Estudios Estratégicos, Documento de opinión, 64bis/2016, del 24 de junio de 2016, pp. 11 y 12.

91 Reinares, Fernando y García-Calvo, Carola, “Brexit, terrorismo y antiterrorismo”, Real Instituto Elcano, Comentario Elcano 26/2016. 
Su salida de la UE implicaría también la pérdida del estatuto de miembro en Europol (cooperación policial) y en Eurojust (cooperación judicial), que son los "instrumentos que coordinan la lucha contra la delincuencia grave y organizada entre los Estados de la UE”. ${ }^{92}$ Por lo demás, resulta más complicado realizar una afirmación tajante acerca de que la retirada del Reino Unido implique la exclusión también del Sistema de Información II, la base de datos que contiene información compartida por todos los Estados miembros sobre sospechosos y delincuentes. ${ }^{93}$

Con todas estas dudas en el horizonte, no es casualidad que los jefes de Estado y de gobierno de los restantes Estados miembros de la UE, reunidos en Bratislava ya en el mes de septiembre, se hayan manifestado (aunque sea tímidamente) a favor de intensificar la cooperación en materia de seguridad interna, defensa y lucha contra el terrorismo. ${ }^{94}$ Tendremos que estar atentos en los próximos meses para ver si estas intenciones se consuman.

\section{CONCLUSIONES}

Algún autor ha señalado que el Brexit supone el final de una etapa histórica importante: la surgida tras la Segunda Guerra Mundial. ${ }^{95}$ En todo caso, es

92 Mangas Martin, Araceli, “¿Brexit? Escenarios internacionales y Gibraltar”, Real Instituto Elcano, Documento de trabajo 9/2016, 17 de junio de 2016, p. 12.

93 Sobre el Sistema de Información de Schengen, véase el Reglamento 1987/2006 del Parlamento Europeo y del Consejo, del 20 de diciembre de 2006, relativo al establecimiento, funcionamiento y utilización del Sistema de Información de Schengen de segunda generación (SIS II), publicado oficialmente en Diario Oficial de la Unión Europea, núm. L381, del 28 de diciembre de 2006, pp. 4 y ss., y la Decisión 2007/533/JAI del Consejo, del 12 de junio de 2007, relativa al establecimiento, funcionamiento y utilización del Sistema de Información de Schengen de segunda generación (SIS II), publicada oficialmente en Diario Oficial de la Unión Europea, núm. L205, del 7 de agosto de 2007, pp. 63 y ss.Y, en relación con la participación del Reino Unido, la Decisión 2016/809, de la Comisión de 20 de mayo de 2016, relativa a la notificación por parte del Reino Unido de Gran Bretaña e Irlanda del Norte de su deseo de participar en determinados actos de la Unión en el ámbito de la cooperación policial adoptados antes de la entrada en vigor del Tratado de Lisboa y que no forman parte del acervo de Schengen, publicada oficialmente en el Diario Oficial de la Unión Europea, núm. L132, del 21 de mayo de 2016, pp. 105 y ss.

94 Puede verse, por ejemplo, Rankin, Jennifer, "Bratislava Summit: EU is at critical point, says Angela Merkel”, The Guardian, 16 de septiembre de 2016.

95 Avbelj, Matej, “Brexit: An End...”, cit., pp. 1 y ss. 
Esta revista forma parte del acervo de la Biblioteca Jurídica Virtual del Instituto de Investigaciones Jurídicas de la UNAM

un intento por volver al pasado, en un mundo cada vez más globalizado y cambiante a gran velocidad, en el que los riesgos que nos amenazan son igualmente globales. La vuelta al localismo y a la individualidad no parece una acertada decisión para enfrentar un futuro exitoso, pero sólo el tiempo nos dirá si la opción adoptada por la población británica es o no acertada y les procura un horizonte mejor del que han disfrutado hasta el momento.

La situación presenciada en el Reino Unido ha deteriorado la imagen de seriedad de la que gozaba este Estado, aunque sólo sea porque ha demostrado la imprevisión del resultado, pues claramente carecían de un plan aplicable si este se producía. No era difícil considerar esta posibilidad teniendo en cuenta lo que avanzaban las encuestas en relación con el equilibrio entre las alternativas formuladas. No olvidemos que sólo eran dos los eventuales resultados: Brexit o Bremain, pero no habían trabajado la primera de ellas. Lo plausible hubiera sido que el día siguiente al referéndum el premier británico planteara unas propuestas para iniciar el trámite de desconexión, en lugar de abandonar el barco y dejar en manos de un sucesor, sin identificar en aquel momento, la tarea de reparar las consecuencias de su imprevisión.

También ha deteriorado la imagen de la Unión Europea que se ubica ante un reto que no había tenido la oportunidad de enfrentar hasta este momento. Se trata de una organización internacional cerrada cuyo acceso se somete a férreas condiciones que son vigiladas y supervisadas de cerca por sus propias instituciones. Con ocasión del Tratado modificativo de los tratados constitutivos adoptado en Lisboa se introdujo el artículo 50 en elTUE, quizá pensando que nunca se utilizaría y tras algo más de siete años ya se ha puesto a prueba. Tanto en la UE como entre quienes contemplan desde fuera esta separación se observa la reducción del número de sus miembros como un fracaso. Incluso hay quienes han comenzado a hablar del inicio del fin de la Unión Europea, objetivo fijado como propio por distintos líderes populistas del continente.

Muchos de los autores que han trabajado sobre el Brexit y que citamos en este trabajo afirman con claridad que en la negociación que se emprenderá en aplicación del artículo 50 del TUE el sujeto principalmente interesado es el Reino Unido, que intentará mantener o de algún modo no perder completamente las posibilidades que la pertenencia a la Unión Europea le ofrece, ni los beneficios que le proporciona. Sin embargo, el interesado carece de la capacidad para decidir por sí solo el modelo de relaciones que articulará en el futuro sus relaciones con la Organización en la que, 
por el momento, cuenta con el estatuto de miembro. El acuerdo habrá de ser fruto del consenso de la Unión Europea y el Reino Unido, en él deben participar las dos partes y ambas tendrán que consentir en él.

Por su parte, la Unión Europea tiene una importante tarea por delante, que no es otra que repensarse y salir fortalecida de esta crisis. Su capacidad para salir fortalecida de situaciones críticas, cual ave fénix, es un rasgo característico de esta organización. Sin embargo, esta vez deberá hacerlo superando unas desavenencias crecientes en su seno entre Estados miembros mucho más heterogéneos tras las últimas ampliaciones. Esperemos que esta ocasión sea una prueba más de esa naturaleza de superación, que parece que sólo podrá ser lograda exitosamente profundizando en la unión. Sobreponerse a esta crisis pasa necesariamente por la adopción de políticas que generen mayor proximidad ciudadana a la UE, en lugar del rechazo que ahora le amenaza como consecuencia de las medidas de austeridad adoptadas frente a la crisis económica y del crónico déficit democrático que se achaca a la Organización, ya sea real o, no menos importante, una percepción. Como avanza Bernard-Henry Levy, "estamos navegando sin brújula"96 y hemos de llegar a un puerto seguro.

Lo que es cierto es que las Comunidades Europeas existían antes de la adhesión del Reino Unido en 1973 y la Unión Europea existirá después de su desconexión. Ambos deberán, a partir de la entrada en vigor del tratado en el que se resuelven las cuestiones planteadas por su divorcio, establecer sus vidas separadas. Ambos tienen una ocasión estupenda para redefinir qué quieren ser en el futuro y cómo pretenden resolver los problemas que la nueva existencia les suscita. Desde la perspectiva de la Unión Europea, es un momento ilusionante en el que se han de resolver múltiples incógnitas. Entre ellas su futuro pasa por decidir si se rendirá definitivamente a una Europa a varias velocidades, si optará por una mayor integración, o si es el momento de corregir (o no) los problemas que surgieron cuando se optó por la ampliación territorial de la UE en lugar de la profundización en la integración de los Estados que participaban entonces en ella.

Como todo divorcio, supone la oportunidad de dar un paso adelante tras reflexionar detenidamente sobre lo que queremos que sea nuestro futuro a medio y largo plazo, y adoptar las medidas para lograrlo. Sin embargo,

96 Véase el interesante comentario de Levy, Bernard-Henry, “Después del Brexit", El País, 11 de julio de 2016. 
en este camino no puede omitirse una tarea importante: es el momento de resolver las decisiones europeas o las estrategias que han motivado la desafección ciudadana y han servido para que, en la actualidad, fueran escasos los Estados miembros de la UE en los que si se realizara un referéndum en términos parecidos a los del Reino Unido, se obtendría un resultado muy diferente. Es preciso reparar los errores cometidos y procurar que la Unión Europea deje de ser ese ente hostil del que vienen los recortes y el empeoramiento de la calidad de vida de los ciudadanos mientras entre todos hemos de pagar los desmanes de los banqueros o de quienes no hacen bien las cuentas. Hay que concebir una Europa que de verdad responda a la ciudadanía y sea capaz de actuar en defensa de los intereses generales y no de los de unos pocos privilegiados y adinerados. Por tanto, es el momento y tenemos la ocasión de cambiar de rumbo, lo que necesitamos ahora es tener la fuerza y la capacidad para que de esta Europa desafecta nazca una unión más fuerte, resolutiva y cercana a los ciudadanos.

\section{BIBLIOGRAFÍA}

AlCAide FernándeZ, Joaquín y CASAdo Raigón, Rafael (coords.), Curso de Derecho de la Unión Europea, Madrid, Tecnos, 2011.

ArTeAgA, Félix, "Brexit me, Brexit me mucho...", Real Instituto Elcano, disponible en: http: / / www.blog.rielcano.org/brexit-me-brexit-me-mucho.

AvbelJ, Matej, "Brexit: An End to the End History", German Law Journal, vol. 17, Brexit supplement, 2016.

BREIDLID, Jacqueline y NAJY, Cenni, "Plan B after Brexit. What Britain can expect negotiating a Swiss-Type Arrangement with the EU”, Foraus-Swiss Forum on Foreign Policy, Policy Brief, junio de 2016.

CARrasco PERERA, Ángel, “«Brexit»y algunos bonitos problemas jurídicos que acarrearía la salida británica de la Unión Europea”, Actualidad Jurídica Aranzadi, núm. 918/2016, 4 de julio de 2016.

CHOPIN, Thierry y JAMET, Jean-François, “After de UK's EU referéndum: redefining relations between the 'two Europes'", European issues, Fondation Robert Schuman, núm. 399, 5 de julio de 2016.

Círculo Cívico DE OPINIÓn, "El Brexit y los intereses económicos españoles”, documento núm. 18, junio de 2016. 
Esta revista forma parte del acervo de la Biblioteca Jurídica Virtual del Instituto de Investigaciones Jurídicas de la UNAM

Delgado Casteleiro, Andrés, "Brexit, el artículo 50 TUE y la repatriación de la política comercial”, Fundación para la Investigación sobre el Derecho y la Empresa, disponible en: http: / / www.fidefundacion.es / BrexitEl-Articulo-50-TUE-y-la-repatriacion-de-la-politica-comercial_a367.html.

DELOY, Corinne, "Supporters and Adversaries to the UK Remaining in the European Union are Running Neck and Neck in the Polls Just One Month Before the Referéndum", Political Issues. Referendum in United Kingdom, Fondation Robert Schuman, 2016.

DíEZ-Hochleitner RodrígueZ, Javier, "La aplicación judicial del derecho de la Unión Europea en España”, Anales de la Academia Matritense del Notariado, t. 50, 2010, pp. 33 y ss.

EKINS, Richard, “The Legitimacy of the Brexit Referendum”, disponible en: https: / /ukconstitutionallaw.org/2016/06/29/richard-ekins-the-legitim acy-of-the-brexit-referendum/.

Fernández NavarRete, Fernando y Fernández Egea, Rosa María, Historia de la Unión Europea. España como Estado miembro, Madrid, Delta, 2010. GRACIA, Manuel, “¿Qué fue del Imperio Británico?: Reino Unido en la Globalización”, Real Instituto Elcano, ARI 45 / 2016, del 7 de junio de 2016. Guinea LlOREnTE, Mercedes, "El Reino Unido y la renegociación de su estatuto de miembro de la Unión Europea”, Revista Aranzadi Unión Europea, núm. 4, 2016, pp. 63 y ss.

Hess, Burkhard y ReQUEJO IsIDRO, Marta, "Brexit: las consecuencias sobre Londres como plaza judicial”, en inglés en Kluwer Arbitration Blog, http: / / kluwerarbitrationblog.com/; en español en el de Aquiescencia, https:// aquiescencia.net/.

LEVY, Bernard-Henry, “Después del Brexit”, El País, de 11 de julio de 2016. Mangas Martín, Araceli, "Sorprendente caja de Pandora británica”, Opinión, El Mundo, 30 de junio de 2016.

, "Referéndum sobre la permanencia del Reino Unido en la UE: consecuencias", Cuadernos del Circulo cívico de opinión, núm. 18, junio 2016,

, “¿Brexit? Escenarios internacionales y Gibraltar”, Real Instituto Elcano, Documento de trabajo 9/2016, 17 de junio de 2016.

, "Dilemas del Reino Unido y de la Unión Europea ¿salir o cambiar la Unión?”, en Real Instituto Elcano, Documento de Trabajo 3/2016, 25 de febrero de 2016. 
y Liñán NogUERAS, Diego Javier, Instituciones y Derecho de la Unión Europea, Madrid, McGraw Hill, 1996 (8a. ed., Madrid, Tecnos, 2014).

MONTOYA CERIO, Fernando, “«Brexit» ficción o realidad: impacto sobre la PESCD de la UE”, en Instituto Español de Estudios Estratégicos, Documento de opinión, 64bis/2016, 24 de junio de 2016.

OrTega, Andrés, “¿«Arrepentexit», o retraso indefinido?”, blog del Real Instituto Elcano, disponible en: http: / / www.blog.rielcano.org/arrepentexito-retraso-indefinido/.

ReInARES, Fernando y GARcÍA-CALVO, Carola, "Brexit, terrorismo y antiterrorismo”, Real Instituto Elcano, Comentario Elcano 26/2016.

RIORDAN, Shaun, “«Brexit»: implicaciones para la seguridad europea”, Instituto Español de Estudios Estratégicos, Documento de opinión, núm. 63bis/2016, 23 de junio de 2016.

RoCHEL, Johan, “La Suisse et l'Union européenne: Pour une association active et flexible", Foraus-Forum de politique étrangere, Papier de discussion núm. 29, junio de 2016.

RogOFF, Kennet, "Britain's Democratic Failure”, disponible en: https: / / www. project-syndicate.org/commentary / brexit-democratic-failure-for-uk-bykenneth-rogoff-2016-06.

KARIM, Sajjad, "Brexit Will Destroy the City of London as we Know it", disponible en: https: / / www.euractiv.com/section/uk-europe/opinion / brexitwill-destroy-the-city-of-london-as-we-know-it/.

TiTOs, Enrique, "El impacto del Brexit en la prestación de servicios financieros por el Reino Unido”, Fundación para la Investigación sobre el Derecho y la Empresa (FIDE), disponible en: http: / / www.fidefundacion.es. 